\title{
Mutation analysis concerning possibility of cancer of unknown primary new treatment
}

\author{
Shoichiro Ohta ${ }^{1 *}$, Yukiko Cho ${ }^{1}$, Yasuharu Onishi ${ }^{2}$, Kazuhiko Juni ${ }^{3}$, Shinji Oshima ${ }^{3}$, Osamu Hosoya ${ }^{3}$, Nobuhiro Yasuno ${ }^{4}$, Tatsuo lijima ${ }^{1}$, \\ Hitoaki Saito' ${ }^{1}$, Masahiko Tanaka ${ }^{4}$ and Hiroshi Kojima' ${ }^{1}$ \\ *Correspondence: sohtajp@josai.ac.jp \\ 'Ibaraki Prefectural Central Hospital and Ibaraki Resional Cancer Center, Japan. \\ ${ }^{2}$ Division of Tranplantation Surgery, Nagoya University Hospital, Nagoya, Japan. \\ ${ }^{3}$ Faculty of Pharmaceutical Sciences, Josai University, Sakado, Saitama, Japan. \\ ${ }^{4}$ Kan-Etsu Hospital,Tsurugashima, Saitama, Japan.
}

\begin{abstract}
Anti-epidermal growth factor receptor monoclonal antibodies are approved and effective only in KRAS wild-type patients with advanced colorectal carcinoma. The present retrospective study investigated the role of KRAS gene mutations and other clinical features in patients with cancer of unknown primary site (CUP). The metastases from two male patients of an unknown primary tumor were included in this retrospective analysis. Both cases were determined cancer of unknown primary by clinicopathologic findings. The KRAS, BRAF, and PI3KCA mutational analyses were performed by means of PCR using genomic DNA for each PCR reaction. All PCR products were directly sequenced. PIK3CA mutation was found in case 1 at exon 9 in this study. This study further investigated the role of KRAS, PIK3CA, and BRAF gene mutations and clinical features for possibilities for new therapies in patients with additional CUP cases. It has been discussed protocols of EGFR blockade and gene-mutation status for extension of indication. The possibility for EGFR blockade to be effective for new indications has been revealed.
\end{abstract}

Keywords: EGFR, KRAS, cancer of unknown primary

\section{Background}

Various guidelines have been suggested for appropriate evaluation of metastatic cancers when the primary tumor site is not readily identifiable based on the clinical presentation, tissue histology and immunohistochemical staining. After such evaluation, cancer of unknown primary (CUP) is the diagnosis made in about $4-5 \%$ of invasive cancers [1-3]. he development of epidermal growth factor receptor (EGFR)-targeting drugs, used both in conjunction with standard care and also as a single therapy, has drastically changed the management of colorectal cancer. Recently, EGFR blockade has become a major research focus, and a number of clinical researches on this new treatment have been started in the field of clinical oncology [4]. Certain mutations in the KRAS gene are currently the most widely used predictors for the effectiveness of EGFRinhibiting drugs in colorectal cancer. The present retrospective study investigated the role of KRAS gene mutations and other clinical features in patients with cancer of unknown primary site (CUP) $[5,6]$. We have analyzed additional cases with the recently improved methods for KRAS analysis and report the data of these cases.

\section{Patients and Methods}

The metastases from two male patients of an unknown primary tumor were included in this retrospective analysis. The definition of CUP syndrome covers patients with histologically confirmed metastatic cancer, when the combination of a complete medical history, accurate physical examination and laboratory tests, and conventional diagnostic imaging procedures (i.e. chest X-ray, abdominal ultrasonograph, and, on the basis of suspected primary disease, $\mathrm{CT}$, magnetic resonance imaging, PET, mammography, and endoscopic procedures) have failed to identify the primary site. The histological types by needle biopsy and sites of our patients' metastases are summarized in Table 1. The blood concentrations of CA19-9, CA15-3, CA125, and carcinoembryonic antigen (CEA) and the most commonly used markers-the leukocyte common antigen, cytokeratins, chromogranin, and vimentin-were assessed for histopathological diagnosis.

Each of these cases was found as a large abdominal tumor and from diagnostic imaging it was not clear whether it was developed intraperitoneally or retroperitoneally. Histopathological diagnosis was conducted in each case by needle biopsy, and in the Case 1, development of poorly- 
Table 1. Clinicopathologic findings.

\begin{tabular}{|c|c|c|c|c|c|c|c|}
\hline Case & sex & age & PS Pathological diagnosis & Positive marker & Treatment & Prognosis & Tuı \\
\hline 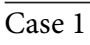 & $\mathrm{M}$ & 75 & 1 & vime & ADM, IFM & $4 \mathrm{M}$ & \\
\hline Case 2 & M & 70 & 1 adenocarcinoma & ND & GEM & $3 \mathrm{M}$ & abdomen \\
\hline
\end{tabular}

Table 2. PIK3CA mutations were found in case 1 at exon 9.

\begin{tabular}{clllll}
\hline Case & \multirow{2}{*}{ KRAS } & $\begin{array}{l}\text { BRAF exon } \\
\text { 15V600E }\end{array}$ & $\begin{array}{l}\text { PI3KCA exon 9 } \\
\text { E542K }\end{array}$ & $\begin{array}{l}\text { PI3KCA exon } \\
\text { 9E545K/D }\end{array}$ & $\begin{array}{l}\text { PI3KCA exon 20 } \\
\text { H1047R }\end{array}$ \\
\hline 1 & ND & GTG & GAA & AAG & CAT \\
2 & ND & GTG & GAA & GAG & CAT \\
\hline \multirow{2}{*}{ Scorpion-arms method } & & &
\end{tabular}

differentiated tumor and non-epithelial tumor were suspected by HE staining and immunostaining respectively. With the Case 2, it was found to be an adenocarcinoma by HE staining, but nothing was found positive in immunostaining and tumormarker-in-the-blood tests. It has not been detected any lesions that was considered primary lesion in such tests as various diagnostic imagings and esophagogastroduodenoscopy, and existence of any blood disorders such as malignant lymphoma was denied. From the above, following the definition, both cases were determined cancer of unknown primary.

DNA extraction from formalin-fixed, paraffin-embedded (FFPE) tumor tissue sections

Tumor cell-rich areas of hematoxylin and eosin-stained sections were marked under a microscope, and tissues were scratched from the same areas of deparaffinized unstained sections. DNA for pieces of the scratched tissue samples was isolated using the QIAamp FFPE Tissue Kit (QIAGEN KK, Tokyo, Japan).

\section{Mutational analyses}

The KRAS, BRAF, and PI3KCA mutational analyses were performed by means of PCR using $100 \mathrm{ng}$ of genomic DNA for each $P C R$ reaction. All PCR products were directly sequenced using an ABI Prism 377 (Applied Biosystems, Foster City, CA) and were then evaluated by means of Sequence Navigator software (Applied Biosystems). Each sequence was carried out at least twice, starting from an independent amplification reaction.

\section{KRAS}

Exon 1 of the KRAS gene was amplified in order to seek potential mutations on the two foremost codons ( 12 and 13), which have been reported as mutated in CRC. PCR amplification was carried out using the Scorpion-arms method and previously described primers and conditions [7].

\section{BRAF}

Exons 11 and 15 of the BRAF gene, including the classical mutation $\mathrm{V} 600 \mathrm{E}$, were amplified using previously described conditions and primers [6].

\section{PI3 KCA}

Exons 9 and 20 of the alpha polypeptide (the catalytic subunit of the PI3K protein, PI3KCA), which are frequently mutated in CRC, were amplified using a standard PCR protocol and previously described primers [7].

\section{Results \\ Clinicopathologic findings}

Both specimens were adenocarcinomas. These two cases received chemotherapy (Table 1). Regarding the clinical data in our cases, it was found that in most of these present cases, histological types could be diagnosed under light microscope, and tissue (including EGFR) and markers in the blood served as auxiliary diagnosis. Markers were particularly useful in diagnosing neuroendocrine tumors.

\section{KRAS, BRAF, and PIK3CA mutations}

Analyzing one representative tumor sample in each patient, we could not find any mutations in the KRAS codon 12 and 13 , or BRAF mutations at codon 600. PIK3CA mutations were found in case 1 at exon 9 (Table 2).

\section{Discussion}

KRAS mutations occur in different tumor types, and are particularly important in colorectal, pancreatic, and NSCLC carcinogenesis [8-12]. KRAS mutations predict a lack of therapeutic benefit of anti-EGFR monoclonal antibodies in colorectal cancer, but this dynamic is more equivocal in lung cancer.

Anti-epidermal growth factor receptor monoclonal antibodies (panitumumab and cetuximab) are approved and effective only in KRAS wild-type patients with advanced colorectal carcinoma [13-16]. The purpose of our meta-analysis was to evaluate the real effects of cetuximab and panitumumab in KRAS wild-type patients treated in randomized trials.

Panitumumab has exhibited promising antitumor activity in several clinical trials, and in 2006 gained FDA approval for the treatment of patients with EGFR-expressing metastatic CRC with disease progression following chemotherapy regimens containing fluoropyrimidine, oxaliplatin, and irinotecan [14].

Some clinical studies were performed for the new indication 
Table 3. KRAS, BRAF, and PIK3CA mutations.

\begin{tabular}{lc}
\hline \multicolumn{1}{c}{-} & KRAS mutation \\
\hline CUP(Ohta et al) & $9 \%$ \\
pancreatic & $56 \%$ \\
colorectal & $51 \%$ \\
uterine & $15 \%$ \\
ovary & $11 \%$ \\
& BRAF mutation \\
CUP(Ohta et al) & $9 \%$ \\
melanoma & $44 \%$ \\
thyroid & $8 \%$ \\
colorectal & $6 \%$ \\
ovary & $5 \%$ \\
& PIK3CA mutation \\
CUP(Ohta et al) & $9 \%$ \\
squamous cervical & $36 \%$ \\
uterine & $25 \%$ \\
breast & $21 \%$ \\
colorectal & $17 \%$ \\
\hline
\end{tabular}

The summary of gene analysis described in the literature and our previous report.

of cetuximab as follow. During a Phase III trial involving 424 patients of untreated head and neck squamous cell carcinoma, the group receiving treatment with a combination of cetuximab and radiation (211 cases) had a median survival period of 49 months and a local control period of 24.4 months, which exceeded the results of radiotherapy-alone group (213 cases) with the median survival period of 29.3 months and the local control period of 14.9 months $[17,18]$. Furthermore, during the Phase III trial involving 442 cases of untreated head and neck squamous cell cancer (relapse or metastasis cases), the group treated with a combination of cetuximab and chemo (222 cases) had a median survival period of 10.1 months, a progression-free survival period of 5.6 months, and a response rate of 36 percent, all of which predominantly exceeded the results of the chemotherapy-only group (220 cases) with the survival period of 7.4 months, the progression-free period of 3.3 months, and the response rate of 20 percent.

During a Phase II trial involving 66 cases of previously treated advanced non-small cell lung cancer, the cetuximabonly treatment resulted in a response rate of 4.5 percent and a disease control rate of 30.3 percent $[11,12]$. As for the results of EGFR-positive cases (60 cases) alone, the cetuximab-only treatment had a response rate of 5.0 percent and a disease control rate of 30.0 percent.

Increasing numbers of studies have reported that information on EGFR mutation is useful when choosing the regimen for treating CRC [7]. Currently several methods are used to investigate EGFR mutation. The characteristics of these methods need to be clarified. For surgically excised specimens consisting mostly of cancer cells, direct sequencing is a good choice to test the mutation. The cancer cell content of the cytological specimens is often much less. When the presence of the cancer cells is confirmed by a pathological examination, the content of cancer cells is usually more than $1 \%$, and high-sensitivity detection methods, like the Scorpion ARMS method are able to detect mutations. A high-sensitivity detection method should be used to detect EGFR mutations from cytological specimens.

Functional RAS may also be potentially important for regulating the actin cytoskeleton, which was suggested as being a critical driver of oncogenic transformation [19]. We analyzed the mutation of same part of these 3 genes in 9 cases of CUP in our previous reports [6] (Table 3), and mutation was detected in one case each of KRAS and BRAF. In the 2 cases analyzed in the present study, mutation was detected in 1 case of PIK3CA (Table 3). The dimension of gene analysis described in the literature is larger and I cannot compare them simply, but I consider that the incidence rates of these gene mutations in CUP are low. Janku et al., found a high prevalence of KRAS mutations in pancreatic $(56 \%)$, colorectal (51\%), uterine (15\%), and ovarian (11\%) cancers, which is similar to previously published findings and data from the COSMIC database (Table 3) $[6,11]$.

BRAF mutations have been mainly reported in melanoma, colorectal, papillary thyroid, and ovarian cancer (Table 3) $[20,21]$. In colorectal cancer they are associated with a poor prognosis; however, unlike KRAS mutations, BRAF mutations might not be predictive of a lack of benefit of cetuximab [22]. In agreement with previously published data, our study showed a high prevalence of BRAF mutations in melanoma (44\%) and, to much lesser extent, in thyroid, colorectal, and ovarian cancer $(8 \%, 6 \%$, and $5 \%$, respectively). In regard to individual aberrations, oncogenic mutations in two hot-spot regions (exons 9 and 20) of PIK3CA have been identified in various malignancies, including common tumors such as breast, lung, colorectal, ovarian and uterine (Table 3) $[6,11]$. In this study, PIK3CA mutations were identified in $11 \%$ of diverse tumor types. Tumors with a high prevalence of PIK3CA mutations were squamous cell cervical (36\%), uterine $(25 \%)$, breast $(21 \%)$, colorectal $(17 \%)$, squamous cell head and neck (15\%), and ovarian cancers (11\%).

\section{Conclusions}

We analyzed KRAS, BRAF, and PI3KCA genes in two CUP cases. PIK3CA mutation was found in case 1 at exon 9 in this study. We have analyzed nine cases of CUP in our previous report and found mutation in one case each of KRAS and BRAF. It has been discussed protocols of EGFR blockade and gene-mutation status for extension of indication. The possibility for EGFR blockade to be effective for new indications has been revealed.

\section{Competing interests}

The authors declare that they have no competing intrests.

\section{Publication history}

Received:12-Nov-2012 Revised: 18-Dec-2012

Accepted: 4-Jan-2013 Published: 09-Jan-2013 


\section{References}

1. Greco F A and Hainsworth J D: Introduction: unknown primary cancer. Semin Oncol 2009, 36:6-7. | Article | PubMed

2. National Comprehensive Cancer Network. Clinical Practice Guidelines in Oncology. Occult Primary (Cancer of Unknown Primary [CUP]) 2011.

3. Greco FA and Hainsworth JD: Cancer of unknown primary; in DeVita VT Jr, Lawrence TS, Rosenberg SA.Cancer Principles and Practice of Oncology, (ed 9.), Lipincott Williams and Wilkens, Philadelphia 2011, 2033-2051.

4. Van Cutsem E, Kohne C H, Lang I, Folprecht G, Nowacki M P, Cascinu S, Shchepotin I, Maurel J, Cunningham D, Tejpar S, Schlichting M, Zubel A, Celik I, Rougier P and Ciardiello F: Cetuximab plus irinotecan, fluorouracil, and leucovorin as first-line treatment for metastatic colorectal cancer: updated analysis of overall survival according to tumor KRAS and BRAF mutation status. J Clin Oncol 2011, 29:2011-9. | Article | PubMed

5. Hainsworth J D and Greco F A: Treatment of patients with cancer of an unknown primary site. N Engl J Med 1993, 329:257-63. | Article | PubMed

6. Ohta S, Cho Y, Shibata M, Nagai K, lijima T, Saito H, Asakura H and Kojima $\mathrm{H}$ : Possibility of molecular targeting therapy for the treatment of cancer of unknown primary origin by analysis of intracellular signaling molecules. Exp Ther Med 2012, 3:547-549. | Article | PubMed Abstract | PubMed Full Text

7. Bando H, Yoshino T, Tsuchihara K, Ogasawara N, Fuse N, Kojima T, Tahara M, Kojima M, Kaneko K, Doi T, Ochiai A, Esumi H and Ohtsu A: KRAS mutations detected by the amplification refractory mutation system-Scorpion assays strongly correlate with therapeutic effect of cetuximab. Br J Cancer 2011, 105:403-6. | Article | PubMed Abstract | PubMed Full Text

8. De Roock W, Claes B, Bernasconi D, De Schutter J, Biesmans B, Fountzilas G, Kalogeras K T, Kotoula V, Papamichael D, Laurent-Puig P, Penault-Llorca F, Rougier P, Vincenzi B, Santini D, Tonini G, Cappuzzo F, Frattini M, Molinari F, Saletti P, De Dosso S, Martini M, Bardelli A, Siena S, Sartore-Bianchi A, Tabernero J, Macarulla T, Di Fiore F, Gangloff A O, Ciardiello F, Pfeiffer P, Qvortrup C, Hansen T P, Van Cutsem E, Piessevaux $H$, Lambrechts $D$, Delorenzi $M$ and Tejpar S: Effects of KRAS, BRAF, NRAS, and PIK3CA mutations on the efficacy of cetuximab plus chemotherapy in chemotherapy-refractory metastatic colorectal cancer: a retrospective consortium analysis. Lancet Oncol 2010, 11:753-62. | Article | PubMed

9. Vogelstein B, Fearon E R, Hamilton S R, Kern S E, Preisinger A C, Leppert M, Nakamura Y, White R, Smits A M and Bos J L: Genetic alterations during colorectal-tumor development. N Engl J Med 1988, 319:525-32. | Article | PubMed

10. Hidalgo M: Pancreatic cancer. N Engl J Med 2010, 362:1605-17. | Article I PubMed

11. Herbst R S, Heymach J V and Lippman S M: Lung cancer. N Engl J Med 2008, 359:1367-80. | Article | PubMed

12. Janku F, Stewart D J and Kurzrock R: Targeted therapy in non-smallcell lung cancer--is it becoming a reality? Nat Rev Clin Oncol 2010, 7:401-14. | Article | PubMed

13. Jonker D J, O'Callaghan C J, Karapetis C S, Zalcberg J R, Tu D, Au H J, Berry S R, Krahn M, Price T, Simes R J, Tebbutt N C, van Hazel G, Wierzbicki R, Langer $\mathrm{C}$ and Moore $\mathrm{M} \mathrm{J}$ : Cetuximab for the treatment of colorectal cancer. N Engl J Med 2007, 357:2040-8. | Article | PubMed

14. Di Nicolantonio F, Martini M, Molinari F, Sartore-Bianchi A, Arena S, Saletti P, De Dosso S, Mazzucchelli L, Frattini M, Siena S and Bardelli A: Wild-type BRAF is required for response to panitumumab or cetuximab in metastatic colorectal cancer. J Clin Oncol 2008, 26:5705-12. | Article | PubMed

15. Sartore-Bianchi A, Martini M, Molinari F, Veronese S, Nichelatti M, Artale S, Di Nicolantonio F, Saletti P, De Dosso S, Mazzucchelli L, Frattini M, Siena S and Bardelli A: PIK3CA mutations in colorectal cancer are associated with clinical resistance to EGFR-targeted monoclonal antibodies. Cancer Res 2009, 69:1851-7. | Article | PubMed

16. Spindler K L, Pallisgaard N, Lindebjerg J, Frifeldt S K and Jakobsen A:
EGFR related mutational status and association to clinical outcome of third-line cetuximab-irinotecan in metastatic colorectal cancer. BMC Cancer 2011, 11:107. | Article | PubMed Abstract | PubMed Full $\underline{\text { Text }}$

17. Bonner J A, Harari P M, Giralt J, Azarnia N, Shin D M, Cohen R B, Jones C U, Sur R, Raben D, Jassem J, Ove R, Kies M S, Baselga J, Youssoufian $\mathrm{H}$, Amellal N, Rowinsky E K and Ang K K: Radiotherapy plus cetuximab for squamous-cell carcinoma of the head and neck. $N$ Engl J Med 2006, 354:567-78. | Article | PubMed

18. Vermorken J B, Mesia R, Rivera F, Remenar E, Kawecki A, Rottey S, Erfan J, Zabolotnyy D, Kienzer H R, Cupissol D, Peyrade F, Benasso M, Vynnychenko I, De Raucourt D, Bokemeyer C, Schueler A, Amellal N and Hitt R: Platinum-based chemotherapy plus cetuximab in head and neck cancer. N Engl J Med 2008, 359:1116-27. | Article | PubMed

19. Xing $M$, Westra $W H$, Tufano $R P$, Cohen $Y$, Rosenbaum $E$, Rhoden $K$ J, Carson K A, Vasko V, Larin A, Tallini G, Tolaney S, Holt E H, Hui P, Umbricht C B, Basaria S, Ewertz M, Tufaro A P, Califano J A, Ringel M D, Zeiger M A, Sidransky D and Ladenson P W: BRAF mutation predicts a poorer clinical prognosis for papillary thyroid cancer. J Clin Endocrinol Metab 2005, 90:6373-9. | Article I PubMed

20. Tol J, Nagtegaal I D and Punt C J: BRAF mutation in metastatic colorectal cancer. N Engl J Med 2009, 361:98-9. I Article I PubMed

21. Kefford R, Arkenau H, Brown MP, M. Millward, J. R. Infante, G. V. Long, D. Ouellet, M. Curtis, P. F. Lebowitz and G. S. Falchook: Phase I/ II study of GSK2118436, a selective inhibitor of oncogenic mutant BRAF kinase, in patients with metastatic melanoma and other solid tumors. J Clin Oncol 2010, 28: ASCO abstract number 8503. | Article

22. Baldus S E, Schaefer K L, Engers R, Hartleb D, Stoecklein N H and Gabbert H E: Prevalence and heterogeneity of KRAS, BRAF, and PIK3CA mutations in primary colorectal adenocarcinomas and their corresponding metastases. Clin Cancer Res 2010, 16:790-9. | Article I PubMed

\section{Citation:}

Ohta S, Cho Y, Onishi Y, Juni K, Oshima S, Hosoya O, Yasuno N, Iijima T, Saito H, Tanaka M and Kojima H: Mutation analysis concerning possibility of cancer of unknown primary new treatment. journal of Cancer Therapeutics and Research 2013, 2:2. http://dx.doi.org/10.7243/2049-7962-2-2 